\title{
MODELING AND PRODUCTIVITY PREDICTION OF THE COMPANIES-INTERNAL CROWDSOURCING-BASED IDEATION
}

\author{
Livotov, Pavel \\ Offenburg University of Applied Sciences
}

\begin{abstract}
The internal crowdsourcing-based ideation within a company can be defined as an involvement of its staff, specialists, managers, and other employees, to propose solution ideas for a pre-defined problem. This paper addresses a question, how many participants of the company-internal ideation process are required to nearly reach the ideation limit for the problems with a finite number of workable solutions. To answer the research question, the author proposes a set of metrics and a non-linear ideation performance function with a positive decreasing slope and ideation limit for the closed-ended problems. Three series of experiments helped to explore relationships between the metric attributes and resulted in a mathematical model which allows companies to predict the productivity metrics of their crowdsourcing ideation activities such as quantity of different ideas and ideation limit as a function of the number of contributors, their average personal creativity and ideation efficiency of a contributors' group.
\end{abstract}

Keywords: New product development, Creativity, Crowdsourcing, Ideation efficiency

\section{Contact:}

Livotov, Pavel

Offenburg University of Applied Sciences

Mechanical and Process Engineering

Germany

pavel.livotov@hs-offenburg.de 


\section{INTRODUCTION}

The crowdsourcing-based ideation belongs to the domain of open innovation and is typically known as outsourcing idea generation to the "crowd" of users (Poetz and Schreier, 2012). The internal crowdsourcing-based ideation within a company can be defined as an involvement of its staff, specialists, managers, and other employees, to propose solution ideas for a pre-defined problem. The outcomes of crowdsourcing idea alerts may result in a high number of ideas which depends on the personal creativity, motivation, qualification, and professional skills of contributing professionals. On the contrary to the outsourcing of ideation to the creativity and experience of a large number of external users (Schemmann et al., 2016), the internal crowdsourcing-based problem solving is characterised by a lower number of unique ideas, depending on the number of participants. The solution space for a problem also varies in case of open-ended or closed-ended problems. Whilst a theoretically unlimited number of feasible solutions is possible for the open-ended problems, the closed-ended problems usually have a limited number of workable solutions (Reinig and Briggs, 2008).

Quantitative research in the field of the companies-internal crowdsourcing-based ideation is rare. In accordance with Osborn (1963) and Valacich et al. (1993), increasing of ideas quantity helps to generate more ideas of higher quality. Diehl and Stroebe (1991) outline a positive correlation of $r=0.82$ between the number of high quality ideas and the total ideas number, and advocate that the quantity metric is also representative for the time-costly quality assessment. On the other hand, Briggs and Reinig (2010) underline that the idea quantity does not necessarily increase the number of "good" ideas. There are several studies on evaluating ideation quality proposing various metrics for quality rating (Shah et al., 2003, Dean et al., 2006, Reinig et al., 2007, Kudrowitz and Wallace, 2012). The quality metrics may vary depending on the stage of problem solving or product development. In this context, the ideation quality function can be defined as a relationship between the number of high-quality ideas and the total number of proposed ideas. Depending on the solution space boundaries, one can differentiate between the uniform ideation function with a constant slope and the non-linear ideation function with positive decreasing slope, which is more typical for closed-ended problems (Reinig et al., 2007). Moreover, according with the Bounded Ideation Theory (Briggs and Reinig, 2010) the upper value of the highquality solution ideas for the closed-ended problems is limited. However, the quantitative data in this field, especially for the crowdsourcing-based ideation, is lacking. Among typical objective metrics of ideation effectiveness such as quantity, variety, novelty, quality, and feasibility of proposed ideas (Shah et al., 2003), only the quantity of ideas can be evaluated fast and exactly, especially in case of high total ideas number typical for crowdsourcing-based ideation. Howard et al. (2010) underline that having a guided approach and creative stimuli are beneficial in terms of increasing creative performance within companies. In a series of experiments performed by Belski et al. (2016) and Livotov (2020) was found that simple engineering creativity techniques significantly improve idea generation performance of students and specialists. Wooten and Ulrich (2015) investigate the open innovation contest approaches with a visibility of submitted ideas by all participants and show that entry visibility generates more entries by increasing the number of participants. At the same time, the quality of submitted ideas increases when the participants cannot see the work of others.

This paper is addressing the quantitative aspects of the companies-internal crowdsourcing-based ideation for the closed-ended problems, such as productivity and efficiency. It also investigates a question on how many ideation process participants are required to nearly reach the ideation limit for the closed-ended problems. To answer this question, the author run a series of ideation experiments, analysed empirical data, and described the experimental results with a mathematical model, which helps to predict the quantity of different ideas and the ideation limit of crowdsourcing-based ideation as a function of the number of contributors and of the average individual and group creativity metrics. Finally, the study explores the impact of different creativity stimuli on ideation outcomes.

\section{EXPERIMENTAL METHOD}

In the initial experiment a closed-ended problem in the field of road condition monitoring by the selfdriving cars has been offered to the interdisciplinary group of engineers and two groups of mechanical and process engineering students, as presented in Table 1. The proposed problem was pre-formulated and introduced to all experiment participants in same manner as follows: "A sensor, for example a camera, for detection of road condition (dry, wet, dirty, icy) is placed in a vehicle close to the road surface to detect its properties. This working principle requires a protection of the sensor from getting 
dirty or damages". The participants of all groups worked individually using the standard ideation form with 5 analogies-based heuristics, presented in the Appendix. The ideation session lasted $20 \ldots 30$ minutes with about $4 \ldots 6$ minutes for each heuristic to limit fatigue and still allow to produce a high quantity of ideas. In each group the participants were sitting together in familiar locations in a large seminar room and were supervised by the same instructor. The problem was new to the participants and had been explained by the supervisor just minutes before the ideation session. After $4 . . .5$ minutes of problem introduction, the participants were allowed to think of the ideas in silence and to write down as many ideas as possible using the distributed idea generation forms. The experiment participation was voluntary and anonymous. The number of different ideas proposed by each individual participant and the number of different ideas within each group were estimated by two independent assessors.

\section{Table 1. Participants groups in the first series of experiments}

\begin{tabular}{|l|c|}
\hline Group 1 & $\begin{array}{c}40 \text { undergraduate students in } 4^{\text {th }} \text { semester of Bachelor's Degree programme at the } \\
\text { Offenburg University, Germany: } 15 \text { persons in Mechanical and } 25 \text { in Process Engineering }\end{array}$ \\
\hline Group 2 & $\begin{array}{r}25 \text { graduate students enrolled into the Master's Degree programme in Mechanical } \\
\text { Engineering in } 8^{\text {th }} \text { or } 9^{\text {th }} \text { semesters at the Offenburg University, Germany }\end{array}$ \\
\hline Group 3 & $\begin{array}{c}\text { Interdisciplinary industrial group of } 13 \text { engineers and product designers involved in R\&D } \\
\text { and new product development activities in German companies }\end{array}$ \\
\hline
\end{tabular}

As explained previously, only the following metrics based on the idea's quantity have been used for the ideation performance assessment in the experiments:

- $n$ - number of group members, participated in the ideation session,

- $\quad N_{\mathrm{t}}$ - total number of ideas generated in a group with $n$ members,

- $N_{\mathrm{d}}$ - total number of different (unique) ideas generated in a group,

- $\quad P_{\mathrm{m}}$ - average ideation productivity: mean number of ideas proposed by individual participant within one ideation session $\left(P_{\mathrm{m}}=N_{\mathrm{t}} / n\right)$, a characteristic of ideation quantity,

- $\quad P_{\mathrm{md}}$ - mean number of different (unique) ideas per person within a group with $n$ members in one session $\left(P_{\mathrm{md}}=N_{\mathrm{d}} / n\right)$, a characteristic of ideation quantity and variety,

- $\quad E_{\mathrm{r}}$ - relative efficiency of ideation, defined as quotient of number of different ideas in a group to the total ideas number $\left(E_{\mathrm{r}}=N_{\mathrm{d}} / N_{\mathrm{t}}\right)$ in a group.

The results of the first experiment are presented in Table 2. The study reveals that the individual ideation performance, supported by the systematized analogies-based thinking, continuously grows with the engineering experience. However, participants with lower experience can partially compensate their lower personal ideation productivity $P_{\mathrm{m}}$ with the higher number of contributing persons to achieve a higher total number of different ideas. For example, 40 undergraduate students with $N_{\mathrm{d}}=59$ generated less unique ideas than 25 graduate students with $N_{\mathrm{d}}=73$. At the same time 25 graduate students could propose practically the same number of different ideas as 13 engineers, with $N_{\mathrm{d}}$ equal 73 and 70 , respectively.

The highest ideation productivity $P_{\mathrm{m}}$ with on average 11,69 ideas per person has been achieved by the engineers (group 3). The results also demonstrate a higher degree of creativity of the graduate students (group $2, P_{\mathrm{m}}=9,60$ ) versus the undergraduate students (group $1, P_{\mathrm{m}}=6,78$ ). The following are some outcomes of the Mann-Whitney test that was used for the statistical comparison of responses in the experiments: undergraduate students' group 1 vs. graduate students' group 2 with $Z=-2,97, p<0,01$; graduate students' group 2 vs. industrial group 3 with $Z=-1,40, p<0,1$. Thus, the groups 1,2 and 3 are characterised by the statistically meaningful difference of the average ideation productivity $P_{\mathrm{m}}$. At the same time, the single groups can be considered as homogeneous, as no statistically significant difference in ideation productivity has been found within each group. For example, the undergraduate students' group 1 with on average $P_{\mathrm{m}}=6,78(\mathrm{SD}=2,88)$ consists of 15 mechanical engineering students with $P_{\mathrm{m}}=6,80(\mathrm{SD}=3,17)$ and 25 process engineering students with $P_{\mathrm{m}}=6,76$ ideas per person $(\mathrm{SD}=2,69)$.

Table 2 also presents two virtual inhomogeneous groups: the group 4 merging the undergraduate and graduate students' groups 1 and 2, and additionally the group 5 which combines the students' groups 1 and 2 with the engineer's group 3. The homogeneous groups 1,2 or 3 are more typical for the internal crowdsourcing-based ideation within a company, especially if it mostly involves R\&D specialists, engineers, and product managers. On the contrary, the inhomogeneous groups are usual for the external 
crowdsourcing-based ideation with a significant number of external participants without companiesinternal experience.

Table 2. Ideation performance assessment of the first series of experiments

\begin{tabular}{|l|c|c|c|c|c|c|}
\hline Group & $n$ & $N_{\mathrm{t}}$ & $N_{\mathrm{d}}$ & $P_{\mathrm{m}}$ & $P_{\mathrm{md}}$ & $E_{\mathrm{r}}$ \\
\hline 1. Students (undergraduate) & 40 & 271 & 59 & $6,78(\mathrm{SD}=2,88)$ & 1,48 & $21,8 \%$ \\
\hline 2. Students (graduate) & 25 & 240 & 73 & $9,60(\mathrm{SD}=3,75)$ & 2,92 & $30,4 \%$ \\
\hline 3. Engineers (industrial group) & 13 & 152 & 70 & $11,69(\mathrm{SD}=4,10)$ & 5,38 & $46,1 \%$ \\
\hline 4. Merging of groups 1 and 2 & 65 & 511 & 94 & $7,86(\mathrm{SD}=3,52)$ & 1,45 & $18,4 \%$ \\
\hline 5. Merging of groups 1, 2 and 3 & 78 & 663 & 103 & $8,50(\mathrm{SD}=3,90)$ & 1,32 & $15,5 \%$ \\
\hline
\end{tabular}

The objective of the second series of the crowdsourcing-based ideation experiments was to evaluate the impact of the engineering domain of a problem on the ideation outcomes. For this purpose, 6 independent experiments have been carried out in the German industrial companies from various engineering domains under similar conditions as the in first experiment and with same instructor. The size of the engineer's ideation groups varied between 14 and 17 participants. The members of all groups worked individually within $20 \ldots 30$ minutes using the identical analogies-based heuristics and idea generation forms as in the first experiment (see Appendix). The 6 different engineering problems in the experiments remain undisclosed in this paper. In each idea generation session, the personal contributions have been merged to a joint idea pool, where the duplicate or similar entries were identified and deleted by two supervisors. The key results of the experiments are summarised in Table 3 . The average individual ideation productivity $P_{\mathrm{m}}$ in the second series of experiments varies between 11,71 and 15,73 with a mean value of 14,0 different ideas per person that is slightly higher than the value of $P_{\mathrm{m}}=11,69$ achieved by the engineers from the group 3 in the first experiment, as indicated in Table 2. Despite some variations in outcomes of individual ideation sessions, no significant influence of the problem's engineering domain on the relative ideation efficiency $E_{\mathrm{r}}$ has been identified.

Table 3. Ideation performance assessment of the second series of experiments ( $n$ - number of engineers in a crowdsourcing-based ideation session)

\begin{tabular}{|l|c|c|c|c|c|c|}
\hline Industrial ideation session & $n$ & $N_{\mathrm{t}}$ & $N_{\mathrm{d}}$ & $P_{\mathrm{m}}$ & $P_{\mathrm{md}}$ & $E_{\mathrm{r}}$ \\
\hline 1. Sensor technology & 17 & 220 & 84 & 13,75 & 4,94 & $38,2 \%$ \\
\hline 2. Civil engineering & 16 & 245 & 78 & 15,31 & 4,88 & $31,8 \%$ \\
\hline 3. Bonding technology & 15 & 236 & 93 & 15,73 & 6,20 & $39,4 \%$ \\
\hline 4. Sealing technology & 14 & 188 & 52 & 13,43 & 3,71 & $27,7 \%$ \\
\hline 5. Measuring technique & 15 & 213 & 92 & 14,12 & 6,13 & $43,2 \%$ \\
\hline 6. Medical equipment & 14 & 164 & 51 & 11,71 & 3,64 & $31,1 \%$ \\
\hline Mean values $*$ and their derivatives $* *$ & $15^{*}$ & $210^{* *}$ & $75^{*}$ & $14,0^{*}$ & $5,0^{* *}$ & $35,7 \% * *$ \\
\hline
\end{tabular}

The third experimental series was conducted to verify the previous findings and also to clarify the possible effect of creativity techniques on the outcomes of the crowdsourcing-based ideation. Thirty three students in different semesters of their studies at the Offenburg University of Applied Sciences, Germany participated in the crowdsourcing-based ideation experiment and were assigned randomly to three groups of 11 persons. Each group included 5 graduate students enrolled into their Master's Degree in Mechanical Engineering and 6 undergraduate students of the Bachelor of Mechanical or Process Engineering Degrees. The experiment participation was voluntary.

The experimental problem of vacuum cleaning of carpets was introduced to all groups for $4 \ldots . .5$ minutes in form of the engineering contradiction using the same Power Point slide: the powerful suction carpet nozzle efficiently removes dust, dirt, and pet hair from the carpet (positive function) but can damage carpet fibres (negative property). Similar to the first and second series of experiments, all participants students were asked to record as many ideas as possible. Others than in two previous experiments, the students were advised to apply the MATCEMIBD ideation technique, which in accordance with Belski et al (2016) can effectively guide a user in a manual search of solutions corresponding to the following engineering domains: Mechanical, Acoustic, Thermal, Chemical, Electrical, Magnetic, Intermolecular, Biomimetics, Data processing. All experiment participants were advised in application of the MATCEMIBD ideation tool before the ideation session and were supervised during the experiment by the same tutor. They worked individually within $25 \ldots 30$ minutes using the idea generation form. The 
idea generation forms were independently evaluated by the two assessors, who documented the independent and feasible ideas, suitable for vacuum cleaning of carpets in private households. The results of the third experiment are presented in Table 4. The students' groups 1,2 and 3 show statistically similar values of the average ideation productivity $P_{\mathrm{m}}$ and can be considered as homogeneous. Consequently, the presented data of the merged group 4 combing the groups 1 and 2, and of the group 5 which is combining all groups 1,2 and 3, illustrate the progress in the internal crowdsourcing-based ideation with the increasing number of contributors.

It is also noteworthy that the average individual ideation productivity of the students in third experiment series $P_{\mathrm{m}}=11,42(\mathrm{SD}=3,80)$ is higher the than the average ideation productivity of the students in the first experiment $P_{\mathrm{m}}=7,86(\mathrm{SD}=3,52)$. A possible explanation for this finding is a higher productivity of the MATCEMIBD-heuristic in the third experiment in comparison with the analogies-based creativity technique in the first series of experiments. It is essential to underline that the different difficulty level of problems in the experiments 1 and 3 could also influence the ideation performance of the students.

Table 4. Ideation performance assessment of the third series of experiments ( $n$ - number of participants in a crowdsourcing-based ideation session)

\begin{tabular}{|l|c|c|c|c|c|c|}
\hline Group & $n$ & $N_{\mathrm{t}}$ & $N_{\mathrm{d}}$ & $P_{\mathrm{m}}$ & $P_{\mathrm{md}}$ & $E_{\mathrm{r}}$ \\
\hline 1. Students & 11 & 123 & 59 & $11,18(\mathrm{SD}=4,84)$ & 5,36 & $48,0 \%$ \\
\hline 2. Students & 11 & 121 & 55 & $11,00(\mathrm{SD}=3,10)$ & 5,00 & $45,5 \%$ \\
\hline 3. Students & 11 & 133 & 53 & $12,09(\mathrm{SD}=3,09)$ & 4,82 & $39,8 \%$ \\
\hline 4. Groups 1+2 & 22 & 244 & 79 & $11,09(\mathrm{SD}=4,07)$ & 3,59 & $32,4 \%$ \\
\hline 5. Groups 1+2+3 & 33 & 377 & 86 & $11,42(\mathrm{SD}=3,80)$ & 2,61 & $22,8 \%$ \\
\hline
\end{tabular}

Based on the experiments and observations, the following empirical model has been proposed for estimation of ideation efficiency and performance of the crowdsourcing-based problem solving.

\section{MODELING OF IDEATION EFFICIENCY AND PERFORMANCE}

Assuming that the number of high-quality ideas positively correlates with the total number of proposed ideas, a major outcome of any ideation technique will be the number of different or independent ideas which can be proposed by the group of $n$ contributors $(n \geq 1)$ within a given time. The number of different ideas $N_{\mathrm{d}}$ proposed by a group of contributors in one ideation session divided by the total number of the ideas in the session $N_{\mathrm{t}}$ has been earlier defined as a relative ideation efficiency of a group $E_{\mathrm{r}}$.

The relative ideation efficiency value $E_{\mathrm{r}}=N_{\mathrm{d}} / N_{\mathrm{t}}$ can be influenced by many factors and variables, such as qualification, experience, creativity, or knowledge diversity of individual participants, but also by the group size $n$ and the total number of generated ideas $N_{\text {t. }}$ As shown in Figure 1, the ideation efficiency $E_{\mathrm{r}}$ is continuously falling with increasing number of group participants. In all experiments with $n>20$ the relative ideation efficiency value $E_{\mathrm{r}}$ did not exceed $35 \%$.

Obviously, that in a group consisting of one person $(n=1)$ the number of different ideas $N_{\mathrm{d}}$ equals the total number of ideas $N_{\mathrm{t}}: N_{\mathrm{d}}=N_{\mathrm{t}}$. In a group with an infinite number of members $(n \rightarrow \infty)$ the relative ideation efficiency value $E_{\mathrm{r}}=N_{\mathrm{d}} / N_{\mathrm{t}}$ will tend towards zero $\left(E_{\mathrm{r}} \rightarrow 0\right)$ if a finite total number of solution ideas is presumed. Such assumption is reasonable for the so called closed-ended problems with a finite number of feasible solution alternatives or with a limited solutions space. Under these constrains the following exponential model can be proposed for assessment of the relative ideation efficiency:

$$
E_{\mathrm{r}}=N_{\mathrm{d}} / N_{\mathrm{t}}=\exp \left[-a \cdot(n-I)^{\mathrm{b}}\right]
$$

The coefficients $a$ and $b$ can be determined using existing experimental data for known values of $N_{\mathrm{d}}$, $N_{\mathrm{t}}$ and $n$. Assuming the average individual ideation productivity $P_{\mathrm{m}}$ in a group $\left(P_{\mathrm{m}}=N_{\mathrm{t}} / n\right)$ as a constant, it is possible to determine the ideation performance function as a number of different ideas $N_{\mathrm{d}}$ in a group of $n$ members with the equation (2):

$$
N_{\mathrm{d}}(n)=n \cdot P_{\mathrm{m}} \cdot \exp \left[-a \cdot(n-1)^{\mathrm{b}}\right]
$$

The coefficients $a$ and $b$ vary here between 0 and 1. Furthermore, in accordance with the Bounded Ideation Theory (Briggs and Reinig, 2010), it appears possible to define a maximum number of group members $n_{\max }$ which will reach the ideation limit defined as the maximum quantity of different ideas 
$N_{\mathrm{dmax}}$ generated by a group for a given closed-ended problem. In other words, a group with the number of participants $n>n_{\max }$ will not be able to propose more different ideas than $N_{\mathrm{dmax}}$ value. In this case the formula (2) can be applied in the range between $n=1$ and $n=n_{\max }$ values.

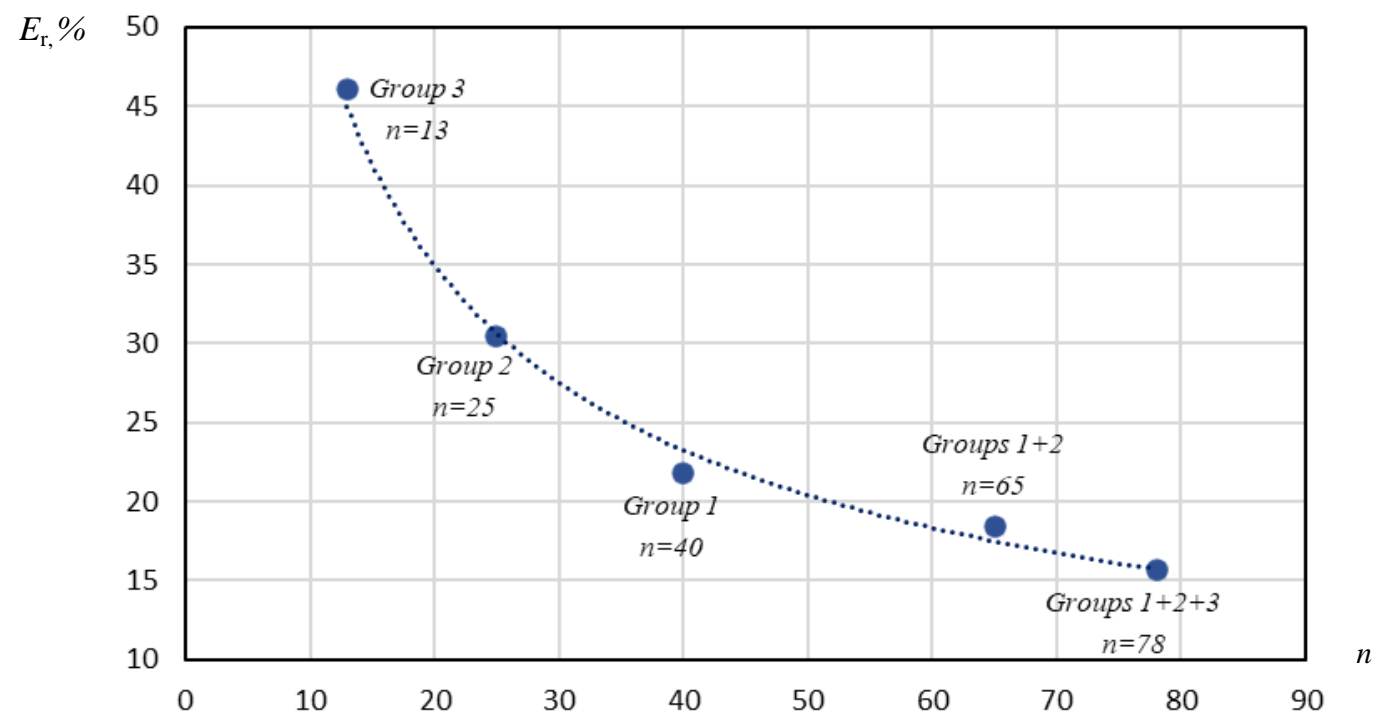

Figure 1. Relative ideation efficiency $E_{r}$ as a function of the group members number $n$ in the first series of experiments

A few reports about the quantitative outcomes of the companies-internal crowdsourcing-based ideation activities and the interviews with the industrial participants of experiments allows to specify a theoretical limit of $n_{\max }=150$ corresponding to the ideation limit $N_{\text {dmax }}$. However, based on the author's practical experience the ideation limit $N_{\mathrm{dmax}}$ for the closed-ended problems with a restricted idea generation time is usually reached by the significantly lower total number of crowdsourcing ideation participants $n$. Thus, the real outcomes of the crowdsourcing ideation are expected to be lower than the values predicted by the model. In the presented study $n_{\max }=150$ is used as a normalization parameter which helps compare the outcomes of different crowdsourcing ideation studies in terms of the proposed model. It should be more accurately specified by future data analysis and research work.

Figure 2 illustrates a calculation example for the homogeneous group 1 of the undergraduate students in the first series of experiments (see Table 2) with $n=40, N_{\mathrm{t}}=271, N_{\mathrm{d}}=59, P_{\mathrm{m}}=6,78, n_{\max }=150, a=$ 0,368 and $b=0,388$. The ideation performance curve $N_{\mathrm{d}}(n)$ hits properly two independent experimental points of group $1 \mathrm{a}\left(n=16 ; N_{\mathrm{d}}=33\right)$ and group $1 \mathrm{~b}\left(n=24 ; N_{\mathrm{d}}=53\right)$ with the relative error between the simulated and experimental values less than $12,9 \%$ (less than 5 ideas in absolute values). Interestingly, the simulation reveals that the assumed maximum number of group members $\left(n_{\max }=150\right)$ leads to the ideation limit of $N_{\mathrm{dmax}}=78$. That means that the undergraduate students using the same ideation technique individually within $20 \ldots 30$ minutes and with the same qualification as in the group 1 most likely will not be able to generate more than 78 different ideas in total, independently of the number of persons participating in the ideation session.

As explained earlier, the coefficients $a$ and $b$ in the ideation performance curve $N_{\mathrm{d}}(n)$ in Figure 2 are determined under empirical assumption of the maximum number of group members $n_{\max }=150$ which corresponds to the ideation limit $N_{\mathrm{dmax}}$ - a theoretical maximum of different ideas generated by a homogeneous group. It is advantageous that in this case only one experimental point $\left(n ; N_{\mathrm{d}}(n)\right)$ is required for the calculation of $a$ and $b$.

The results of the calculations with the formula (2) for the first, second and third series of experiments are presented in Table 5. The ideation limit $N_{\text {dmax }}$ depends on the relative ideation efficiency $E_{\mathrm{r}}$ of a group and on the average individual productivity $P_{\mathrm{m}}$ of the group members. Consequently, the industrial groups in the first and second experiments show higher anticipated ideation limits than the students with respectively $N_{\mathrm{dmax}}=175$ ideas ( $1^{\text {st }}$ experiment) and $N_{\text {dmax }}=160$ ideas ( $2^{\text {nd }}$ experiment, mean values applied). In the first experiment the students' groups demonstrate correspondingly the ideation limit values $N_{\mathrm{dmax}}$ of 78 ideas for the undergraduate group 1 and of 121 ideas for the graduate group 2. The estimated ideation limit of the students' group in the third experiment is equal 122 ideas. 
Table 5 also provides the estimated values of relative ideation efficiency $E_{\mathrm{r}}$ of all groups for two important numbers of crowdsourcing ideation participants: $n_{1}=15$ (a typical group size for internal ideation in companies) and $n_{2}=n_{\max }=150$ (corresponds to the specified ideation limit $N_{\text {dmax }}$ ). It is interesting to note in this context that the ideation efficiency values at $n_{1}=15$ and $n_{2}=150$ of engineers and students are remarkably close to each other. For example, the undergraduate students' group 1 (first experiment) and the engineers' group (second experiment) demonstrate almost the same ideation efficiencies $E_{\mathrm{r}}$. At the same time, the ideation productivity $P_{\mathrm{m}}$ values of students and engineers are clearly different from each other.

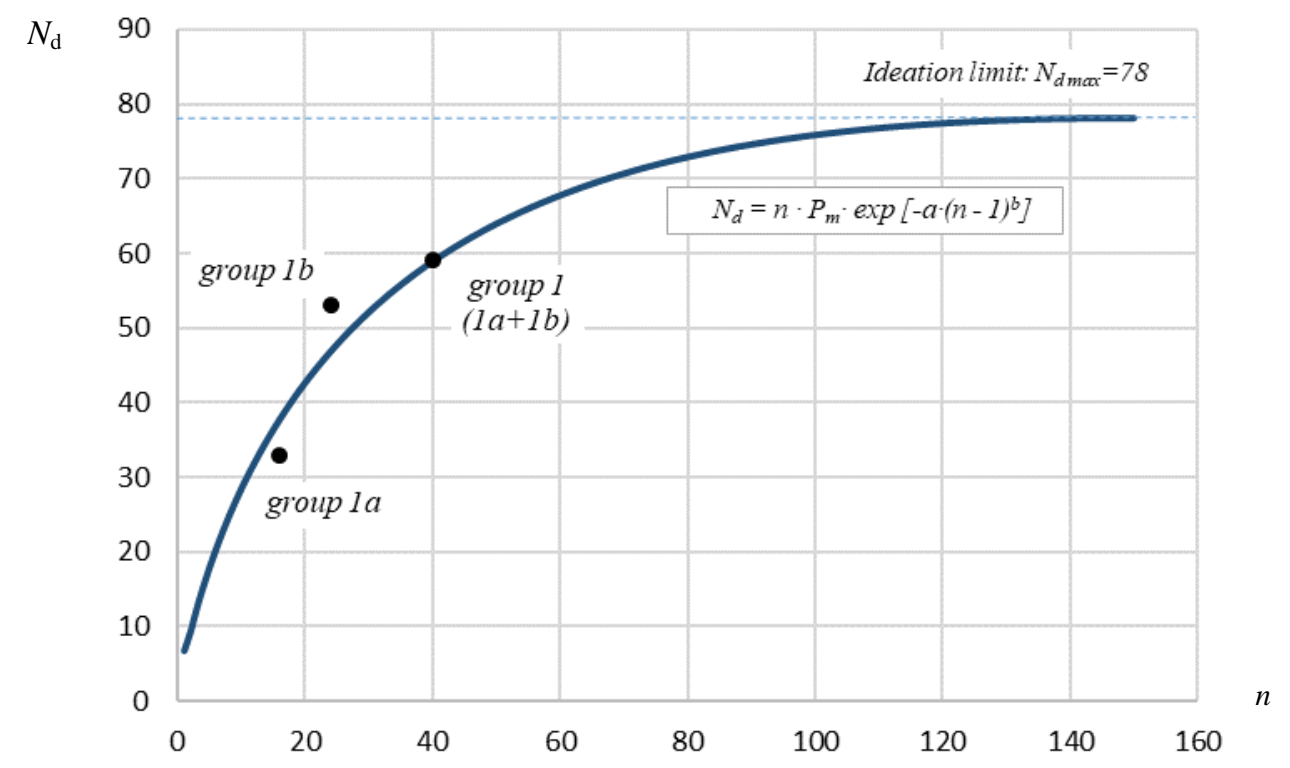

Figure 2. Ideation performance function (2) as a number of different ideas $N_{d}$ dependent on the group members number $n$ for the student's group 1 in the first series of experiments

The proposed ideation performance function (2) allows one also to estimate the number ideation session participants $n_{95}$ which is expected to achieve $95 \%$ of the ideation limit $N_{\mathrm{dmax}}$. For example, the outcomes of the second experiment with 91 engineers (Table 5) can be used for estimation of the crowdsourcing-based ideation performance in the companies with $a=0,371 ; b=0,387 ; P_{\mathrm{m}}=14,0 ; N_{\mathrm{d}}=75$ and $n_{\max }=150$. The group size corresponding to the practical ideation limit of $\left(0,95 \cdot N_{\mathrm{dmax}}\right)=152$ is equal $n_{95}=87$. Remarkably that 87 contributors out of total 150 ideation participants (nearly $58 \%$ ) would be able to generate $95 \%$ of all different ideas. Similar simulation results have been also observed for all experiments.

Finally, the formula (2) allows one to predict the productivity of the crowdsourcing ideation for the closed-ended problems. However, the estimated parameters for productivity prediction in Table 5 are only valid for the individual idea generation supported by applied heuristics and with the average ideation time of $20 \ldots 30 \mathrm{~min}$ per person. For example, the resulting number of different ideas $N_{\mathrm{d}}$ in the crowdsourcing ideation session with 40 engineers $(n=40)$, using five analogies-based heuristics, can be anticipated with different 121 ideas:

$$
N_{\mathrm{d}}(40)=40 \cdot 14 \cdot \exp \left[-0,371 \cdot(25-1)^{0,387}\right] \approx 121
$$

This calculated result is in good agreement with the reported outcomes of the internal crowdsourcing ideation project with 40 participants and 109 different solution ideas in one German medium-sized engineering company.

Thus, the productivity $N_{\mathrm{d}}$ and $N_{\mathrm{dmax}}$ of the crowdsourcing-based ideation is primarily influenced by two apparently independent factors. The first one is the individual ideation productivity $P_{\mathrm{m}}$ which can be considered as constant under the same conditions such as competences and creativity of participants, duration of ideation session and supporting heuristics. The second influencing variable is the relative ideation efficiency $E_{\mathrm{r}}(n)$ which is decreasing with the rising number of ideation participants $n$ in accordance with coefficients $a$ and $b$ in the equation (1). The higher ideation efficiency values in the experiments positively correlate with decreasing form coefficient $a$ and increasing shape coefficient $b$. 
Table 5. Parameters for productivity prediction of crowdsourcing-based ideation for homogeneous groups of participants

\begin{tabular}{|l|l|c|c|c|c|c|c|}
\hline $\begin{array}{l}\text { Number of } \\
\text { experimental } \\
\text { series }\end{array}$ & $\begin{array}{l}\text { Experiment groups } \\
\text { and participants }\end{array}$ & $\begin{array}{l}\text { Ideation } \\
\text { limit }\end{array}$ & $\begin{array}{l}\text { Form } \\
\text { coeff. }\end{array}$ & $\begin{array}{c}\text { Shape } \\
\text { coeff. }\end{array}$ & $\begin{array}{c}\text { Ideation } \\
\text { productivity }\end{array}$ & \multicolumn{2}{|c|}{$\begin{array}{c}\text { Relative ideation } \\
\text { efficiency }\end{array}$} \\
\cline { 2 - 8 } & $N_{\mathrm{dmax}}$ & $a$ & $b$ & $P_{\mathrm{m}}$ & $E_{\mathrm{r}}(n=15)$ & $E_{\mathrm{r}}(n=150)$ \\
\hline 1 & $\begin{array}{l}1 . \text { Undergraduate } \\
\text { students }(n=40)\end{array}$ & 78 & 0,368 & 0,388 & 6,78 & $35,9 \%$ & $7,7 \%$ \\
\hline 1 & $\begin{array}{l}2 . \text { Graduate students } \\
(n=25)\end{array}$ & 121 & 0,333 & 0,401 & 9,60 & $38,3 \%$ & $8,4 \%$ \\
\hline 1 & $\begin{array}{l}3 . \text { Engineers }(n=13) \\
\text { Engineers (mean } \\
\text { values; } n=91)\end{array}$ & 175 & 0,265 & 0,432 & 11,69 & $43,7 \%$ & $10,0 \%$ \\
\hline 3 & $\begin{array}{l}3 . \text { Students } \\
(n=33)\end{array}$ & 122 & 0,401 & 0,377 & 11,42 & $33,8 \%$ & $7,1 \%$ \\
\hline
\end{tabular}

Additionally, for a homogeneous group with a constant ideation productivity $P_{\mathrm{m}}$ of its members the values of the coefficients $a$ and $b$ can be calculated directly using two experimental points with $n=n_{1}$ and $n=n_{2}$ participants and corresponding ideation efficiencies $E_{\mathrm{r} 1}=E_{\mathrm{r}}\left(n_{1}\right)$ and $E_{\mathrm{r} 2}=E_{\mathrm{r}}\left(n_{2}\right)$. The resolution of the equation (1) for these two experimentally determined values leads to:

$$
\left\{\begin{array}{c}
a=-\frac{\ln \left(E\left(n_{2}\right)\right)}{\left(n_{2}-1\right)^{b}} \\
b=\frac{\ln \left(\ln \left(E\left(n_{1}\right)\right) / \ln \left(E\left(n_{2}\right)\right)\right)}{\ln \left(n_{1}-1\right)-\ln \left(n_{2}-1\right)}
\end{array}\right.
$$

The average values of the ideation efficiencies for $n_{1}=15$ and $n_{2}=150$ presented in the Table 5 can be calculated with $E_{\mathrm{r}}\left(n_{1}\right)=0,375$ and $E_{\mathrm{r}}\left(n_{2}\right)=0,082$. So, the application of the formula (4) leads subsequently to the coefficient's values of $a=0,345$ and $b=0,396$. These values can be used for the initial assessment of the crowdsourcing-based ideation outcomes at the planning stage of ideation activities as no experimental data is yet available. For example, Figure 3 illustrates the ideation progress in the third series of experiments presented in the Table 4 with three experimental points: results of the group 1 (number of group members $n=11$ ), merged groups 1 and $2(n=22)$ and finally of all participants (groups 1, 2 and 3 with $n=33$ ). The theoretical ideation performance curve $N_{\mathrm{d}}(n)$ in Figure 3, simulated with the average values $P_{\mathrm{m}}=11, \mathrm{a}=0,345$ and $b=0,396$, is in good accordance with the experimental data.

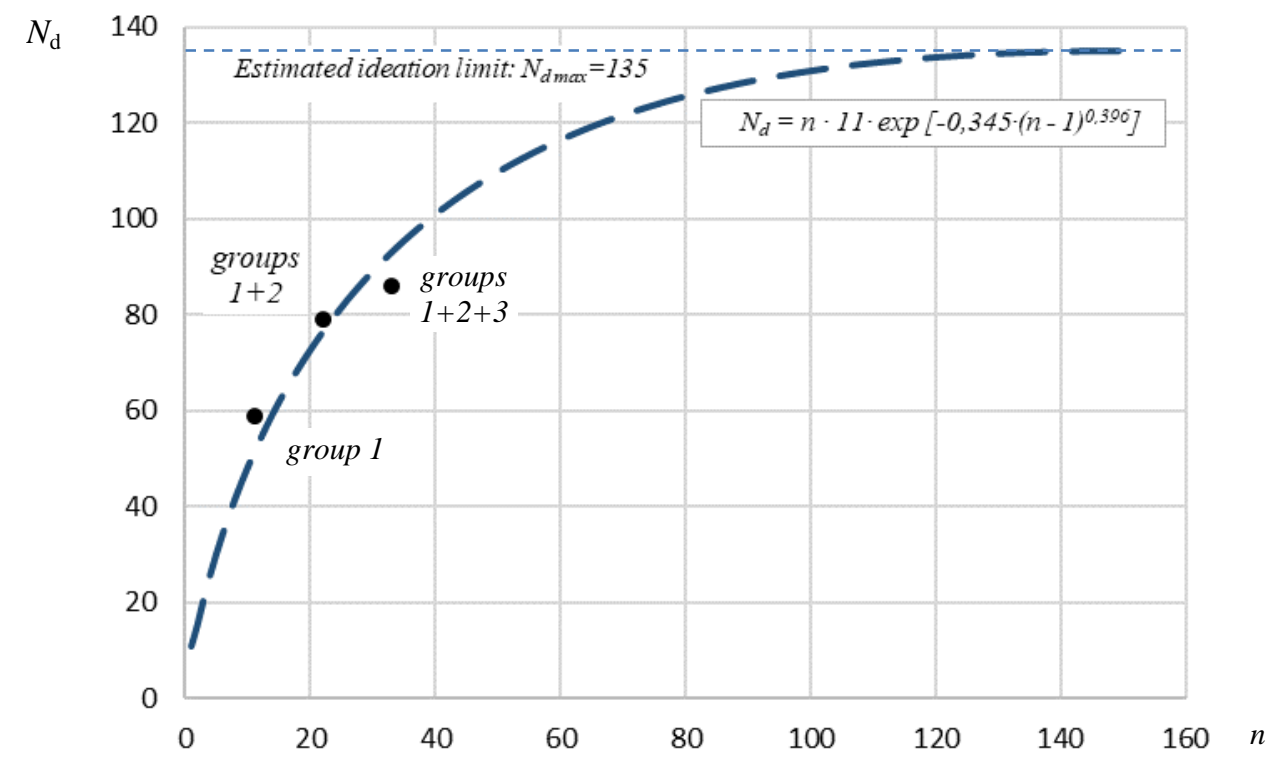

Figure 3. Prediction of the ideation performance $N_{d}$ as a function of the group members number $n$ for the third series of experiments 
A satisfactory match between the experimental data and corresponding estimated values of the ideation performance function (2) has been also observed in other experimental series. Therefore, the following data can be applied for the initial productivity prediction of the crowdsourcing-based solving of closed-ended problems with the formula (2):

- $\quad$ coefficients $a=0,345$ and $b=0,396$,

- average individual ideation productivity for the engineers supported by the creativity techniques $P_{\mathrm{m}}=11 \ldots 14$ and without creative stimuli $P_{\mathrm{m}}=6 \ldots 7$,

- average individual ideation productivity for the students supported by the creativity techniques $P_{\mathrm{m}}=8 \ldots 11$ and without creative stimuli $P_{\mathrm{m}}=4 \ldots 5$.

In accordance with the previous studies on engineering creativity (Belski et al., 2016; Livotov, 2020) the individual ideation performance in sessions without creative stimuli usually results in halving the numbers of ideas per person in comparison with application of engineering creativity tools. However, the recommended $P_{\mathrm{m}}$ values and the coefficients $a=0,345$ and $b=0,396$ are to be understood as rough guide numbers only, and require a systematic experimental validation in future. As outlined above, the real outcomes of the crowdsourcing ideation are expected to be lower than the values predicted by the model. Moreover, the proposed coefficients $a$ and $b$ in the formula (2) for estimating ideation performance function of a group are applicable and valid for the number of ideation participants smaller than $n_{\max }=150$.

\section{CONCLUDING REMARKS AND OUTLOOK}

Addressing the goals of the presented study, the paper analyses the prior work in the field of crowdsourcing-based ideation and proposes a set of metrics and a non-linear ideation performance function with a positive decreasing slope and ideation limit for the closed-ended problems. Three series of experiments helped to explore relationships between the metrics attributes and resulted in a mathematical model which allows companies to predict the productivity of their crowdsourcing ideation activities supported by the simple engineering heuristics.

It was found that the major productivity metrics of the crowdsourcing-based ideation, such as the total number of ideas and the total number of different ideas, are primarily influenced by two apparently independent factors. The first one is the individual ideation productivity which can be considered as constant under the same conditions such as competences and creativity of participants, duration of ideation session and supporting heuristics. The second influencing factor is the efficiency of the crowdsourcing-based ideation, defined as a ratio of number of different ideas to the total ideas number, which is exponentially falling with increasing number of group participants. Such effect is expectable for the closed-ended problems with a finite number of feasible solution alternatives or with a limited solutions space. In accordance with simulations nearly $60 \%$ of ideation participants can generate about $95 \%$ of all expected different ideas for the closed-ended problems.

The ideation efficiency values of engineers and students in the experiments were remarkably close to each other. At the same time, different students' and engineers' groups were characterised by the statistically meaningful difference of the average individual ideation productivity. Moreover, the ideation outcomes of students' groups applying different engineering ideation heuristics show deviating values of individual ideation productivity. However, despite some variations in outcomes of ideation sessions, no significant influence of the problem's engineering domain on the ideation efficiency has been identified.

The future research should focus on the impact of the supporting engineering creativity techniques on ideation outcomes and take into consideration other ideation metrics such as quality, variety, and feasibility. A comparison between the ideation quality function, defined as quotient of number of highquality ideas to the total ideas number, and the proposed ideation performance function will enable practitioners, engineering educators, and creators of ideation methods to view issues in an objective light and to support decision-making in the research and practice.

\section{APPENDIX}

Ideation form applied in the first and second series of experiments.

To help support the engineering creativity of students and specialists, the following heuristics based on five interdisciplinary analogies has been used in the 1 st and 2 nd series of experiments. The primary 
useful function and the negative effect have been clarified with the experiment participants just before the ideation session.

\begin{tabular}{|c|c|c|}
\hline Heuristic & Description & Fields for ideas \\
\hline Analogy 1 & $\begin{array}{l}\text { Think, how is a similar problem solved in technical domains or } \\
\text { fields like yours? }\end{array}$ & \\
\hline Analogy 2 & $\begin{array}{l}\text { Extract the primary useful function. How is a similar useful } \\
\text { function realized in other technical domains? }\end{array}$ & \\
\hline Analogy 3 & $\begin{array}{l}\text { Extract the primary negative effect or harm. How is a similar } \\
\text { negative effect or harm counteracted in other technical } \\
\text { domains? }\end{array}$ & \\
\hline Analogy 4 & $\begin{array}{l}\text { How is similar problem is in very small systems up to the micro } \\
\text { or nano-level and in the huge macro- and giga-systems? }\end{array}$ & \\
\hline Analogy 5 & $\begin{array}{l}\text { How is a similar problem solved in the nature (living organisms, } \\
\text { cells, plants, insects, animals, humans)? }\end{array}$ & \\
\hline
\end{tabular}

\section{REFERENCES}

Belski, I., Livotov, P. and Mayer, O. (2016), "Eight Fields of MATCEMIB Help Students to Generate More Ideas", Procedia CIRP, Vol. 39, pp. 85-90. https://doi.org/10.1016/j.procir.2016.01.170

Briggs, R.O. and Reinig, B.A. (2010), "Bounded Ideation Theory", Journal of Management Information Systems, Vol. 27, Vol. 1, pp. 123-144. http://doi.org/10.2753/MIS0742-1222270106

Dean, D.L., Hender, J.M., Rodgers, T.L. and Santanen, E.B. (2006), "Identifying Quality, Novel, and Creative Ideas: Constructs and Scales for Idea Evaluation", Journal of the Association for Information Systems, Vol. 7, Iss. 10, pp. 646-649. http://doi.org/10.17705/1jais.00106

Diehl, M., and Stroebe, W. (1991), "Productivity loss in idea-generating groups: Tracking down the blocking effect", Journal of Personality and Social Psychology, Vol. 61, No. 3, pp. 392-403

Howard, T.J., Culley, S. and Dekoninck E.A. (2011), "Reuse of ideas and concepts for creative stimuli in engineering design", Journal of Engineering Design, 22:8, pp. 565-581. https://dx.doi.org/10.1080/09544821003598573

Kudrowitz, B.M. and Wallace, D. (2012), “Assessing the quality of ideas from prolific, early-stage product ideation”, Journal of Engineering Design, Vol. 24, No. 2, pp. 120-139. http://doi.org/10.1080/09544828.2012.676633

Livotov, P. (2020), "Easy-to-Use Ideation Technique Based on Five Cross-Industry Analogies Enhances Engineering Creativity of Students and Specialists”. In: Cavallucci D., Brad S., Livotov P. (Eds), Systematic Complex Problem Solving in the Age of Digitalization and Open Innovation, Springer, Cham, pp. 103-121. https://doi.org/10.1007/978-3-030-61295-5_9

Osborn, A.F. (1963), Applied Imagination, Scribner, New York.

Poetz, M.K. and Schreier, M. (2012), "The value of crowdsourcing: can users really compete with professionals in generating new product ideas? ”, Journal of Product Innovation Management, Vol. 29, No. 2, pp. 245-256. http://doi.org/10.1111/j.1540-5885.2011.00893.x

Reinig, B.A., Briggs, R.O. and Nunamaker, J. Jr. (2007), “On the Measurement of Ideation Quality”, Journal of Management Information Systems, Vol. 23, No. 4, pp. 143-161. http://doi.org/10.2753/MIS0742-1222230407

Reinig, B.A. and Briggs, R.O. (2008), "On the relationship between idea-quantity and idea-quality during ideation”, Group Decision and Negotiation, Vol. 17, No. 5, pp. 403-420. https://doi.org/10.1007/s10726008-9105-2

Schemmann, B., Herrmann, A.M., Chappin, M. and Heimeriks, G.J. (2016), "Crowdsourcing ideas: Involving ordinary users in the ideation phase of new product development", Research Policy, Vol. 45, pp. 1145-1154. http://dx.doi.org/10.1016/j.respol.2016.02.003

Shah J. J., Smith, S.M and Vargas-Hernandez, N. (2003), "Metrics for measuring ideation effectiveness", Design Studies, Vol. 24, No. 2, pp. 111-134. https://doi.org/10.1016/S0142-694X(02)00034-0

Valacich, J.S., Dennis, A.R. and Connolly, T. (1994), "Idea generation in computer-based groups: A new ending to an old story", Organizational Behavior and Human Decision Processes, Vol. 57, Iss. 3, pp. 448-467. https://doi.org/10.1006/obhd.1994.1024

Wooten, J.O. and Ulrich, K. (2015), “The Impact of Visibility in Innovation Tournaments: Evidence from Field Experiments", Wooten, Joel O. and Ulrich, Karl T., The Impact of Visibility in Innovation Tournaments: Evidence from Field Experiments, Psychology of Innovation eJournal, 36 pages. http://dx.doi.org/10.2139/ssrn.2214952 